\title{
A theoretical framework for the analysis of residential solid wastes generation and composition (SWGC) in Bauchi metropolis, Nigeria
}

\author{
Adamu Isa Harir ${ }^{1}$, Rozilah Kasim ${ }^{2}$ \& Bala Ishiyaku ${ }^{3}$ \\ ${ }^{1,2,3}$ Department of Construction and Real Estate Management, \\ Faculty of Technology Management, Business and Entrepreneurship, \\ University Tun Hussein Onn Malaysia (UTHM), 86400, Johor, \\ adamuharir@gmail.com¹, rozilah@uthm.edu.my², balaishiyaku@yahoo.com³
}

Keywords: Theoretical framework, Residential Solid Wastes, Solid Wastes Generation, Solid Wastes Composition, Waste management

\begin{abstract}
Solid waste varies extremely in generation rates and types of materials composition across countries and cities or even within the city parts due to changing socio-economic and climate conditions which also differs by location and time. Thus, studies to define these parameters are essential for achieving efficiency of waste management. This paper reviewed literature and proposed a framework for the analysis of residential solid wastes generation and composition (SWGC) in Bauchi metropolis Nigeria, being an extract of $\mathrm{PhD}$ research in progress. The framework suggested a mixed approach using mainly quantitative and the support of qualitative methods. The framework will develop a reliable database to underpin policies for efficient solid waste management in Bauchi metropolis, Nigeria.
\end{abstract}

\section{Background}

Rapidity of population, urbanisation and economic growths have increased solid waste generation rates and material composition [1]. Solid waste generation increased rapidly from 0.49 billion tons in 1997 to 1.9 billion tonnes in 2010 and will reach 27 billion tons by 2050 [2]. Furthermore, the solid waste composition extremely varies across countries, regions and cities or even between different parts of a city. According to Ezeah [3], positive findings are emerging from use of adequate data base to design appropriate policies for solid waste management. However, in developing countries, like Nigeria, lack of data created inefficiencies of solid waste management in many cities. Thus, studies to define solid wastes generation and composition will strongly determine efficiency of solid waste management in Nigeria and other developing countries. Literature indicated lack of definite framework for solid wastes studies which resulted to various approaches in the analysis of solid wastes generation and composition. This suggested the need to propose a framework for solid wastes generation and composition analysis in order to extend the existing body of knowledge.

Many scholars cited lack of data as an important impediment to solid waste management in Nigeria. In Bauchi metropolis reliable data are lacking on solid wastes generation and composition for Bauchi metropolis. However, in Bauchi metropolis climate conditions varies with consistency over the years, between wet and dry seasons while the socio-economic attributes of the population are heterogeneous. The absence of reliable data on the influence of these parameters on generation and composition may be the important challenge in the efforts to achieve efficient solid waste management in the metropolis. Therefore, this study will generate data on solid wastes generation and composition and the factors influencing their variations in different residential areas within Bauchi metropolis. This is expected to provide the data baseline from which to identify an appropriate policy framework that can achieve an efficiency of planning and operations of solid waste management in the metropolis. 


\section{Theoretical Overview}

Solid waste varies in generation rates and compositions between localities due to socio-economic and climate season. This variability makes solid waste data more difficult to achieve, but also most essential for designing effective waste management. According to Ngoc and Schnitzer [4] it is fundamental in waste management to know the pattern of waste generation and their factors. Similarly, Beigl, Sandra \& Stefan [5] opined that solid wastes data is relevant in estimating material recovery, human resource and equipment, physical, chemical and thermal properties as potentials for policy decisions. Data is relevant in evaluating sizes and locating collection facilities and route design for waste disposals. Recent findings as in Ezeah [3] cited positive results from waste management in many parts of the world where reliable data base is used to identify appropriate policies that suit local conditions. Thus, reliable database is necessary to identify appropriate policy for efficient solid waste management in Bauchi metropolis and cities in developing countries.

\section{Factors influencing solid wastes generation and composition}

The influence of social, economic and climate, seasons on solid waste generation has been reported in both developed and developing countries. In the United States of America and the United Kingdom, income and affluence based correlations on wastes parameters are cited. Ojeda-Benitez, Carolina \& Ma [6] observed in Mexico City, solid waste generation increased from lower towards higher income households and Boer, et al. [7], also found in Polish cities income and climate, seasons had influenced wastes compositions. Burnley [8] reviewed solid wastes studies in the United Kingdom found household size and age profile had influenced solid wastes generation and compositions.

In developing countries, Sujauddin, Huda \& Hoque [9] and Dangi [10] showed wastes generation rate differs between higher, middle and lower income household in Bangladesh and Kathmandu cities respectively. Beigl, Sandra \& Stefan [5] observed that solid waste generated is lower in households with elderly couples or singles, than in those with infants and school age children. Household education status influences choice of food and materials consumption and consequently waste generation [11]. Similarly, Yatima and Mohd [12] found in Pataling Jaya, Selangor, Malaysia, that household size and eating habits had influenced solid waste generation.

Household attributes like income, size, education and others are cited as the factors influencing solid waste generation rates and composition [11]. Studies by Burnley [8] in the United Kingdom and Afon \& Afolabi [11] in Oyo city, Nigeria, revealed significant variations in waste generation and composition due to climate seasons. The enforcement of appropriate legislation and policies proved effective in improving solid waste management [12]. Legal framework and government policies in the U. K. had encouraged solid wastes recycling in the $1990^{\mathrm{S}}$ [8]. Yatima and Mohd [12] observed that adequate legislation and enforcement enhanced solid waste management in London city. Carbon purchased credit incentives had discourage carbon releases into the atmosphere while generator pay fees can minimise solid waste generation in cities.

Generally, the influence of these factors on solid wastes generation and composition differs from countries, regions and cities or even between locations within the same city [13]. Thus, the factors correlated significantly with waste generation in some studies, while in some others the correlations are weak [13]. Therefore, both spatial and temporal parameters are relevant in a solid waste analysis, since both changes in location and time can lead to variations in generation and composition. Government regulations such as legislation and policies are also control mechanism relevant to waste management. Adequate environmental laws and enforcement are very relevant mechanism used to control waste generation and achieve efficient solid waste management. 


\section{The philosophy and paradigm of the framework}

The framework adopted a mixed method to answer the what, why and how research questions being relevant to solid waste analysis. The framework philosophy suggested 3 relevant schools of reasoning: ontology, epistemology and axiology (Figure 1). The study paradigm is positivism, which dictated adopting the values of realism and objectivism (Figure 1)

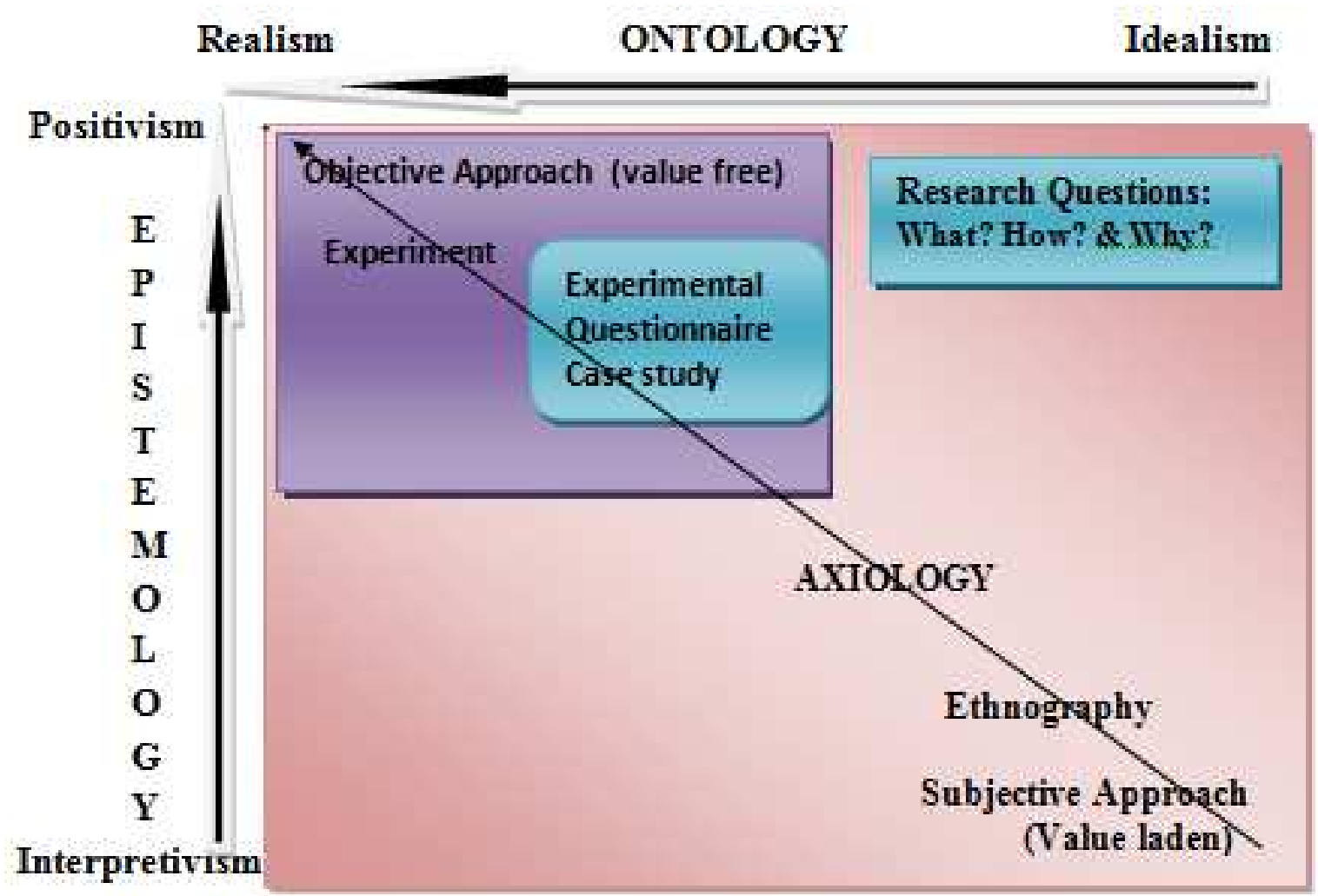

Figure 1: The framework Philosophy and Paradigm

\section{The Proposed Theoretical Framework}

A combination of deductive and inductive approaches to address the what, why and how research questions being relevant to solid waste analysis, dictates using both theories and concepts to identify the focus of investigations appropriate for the desired framework as shown in Figure 2. 


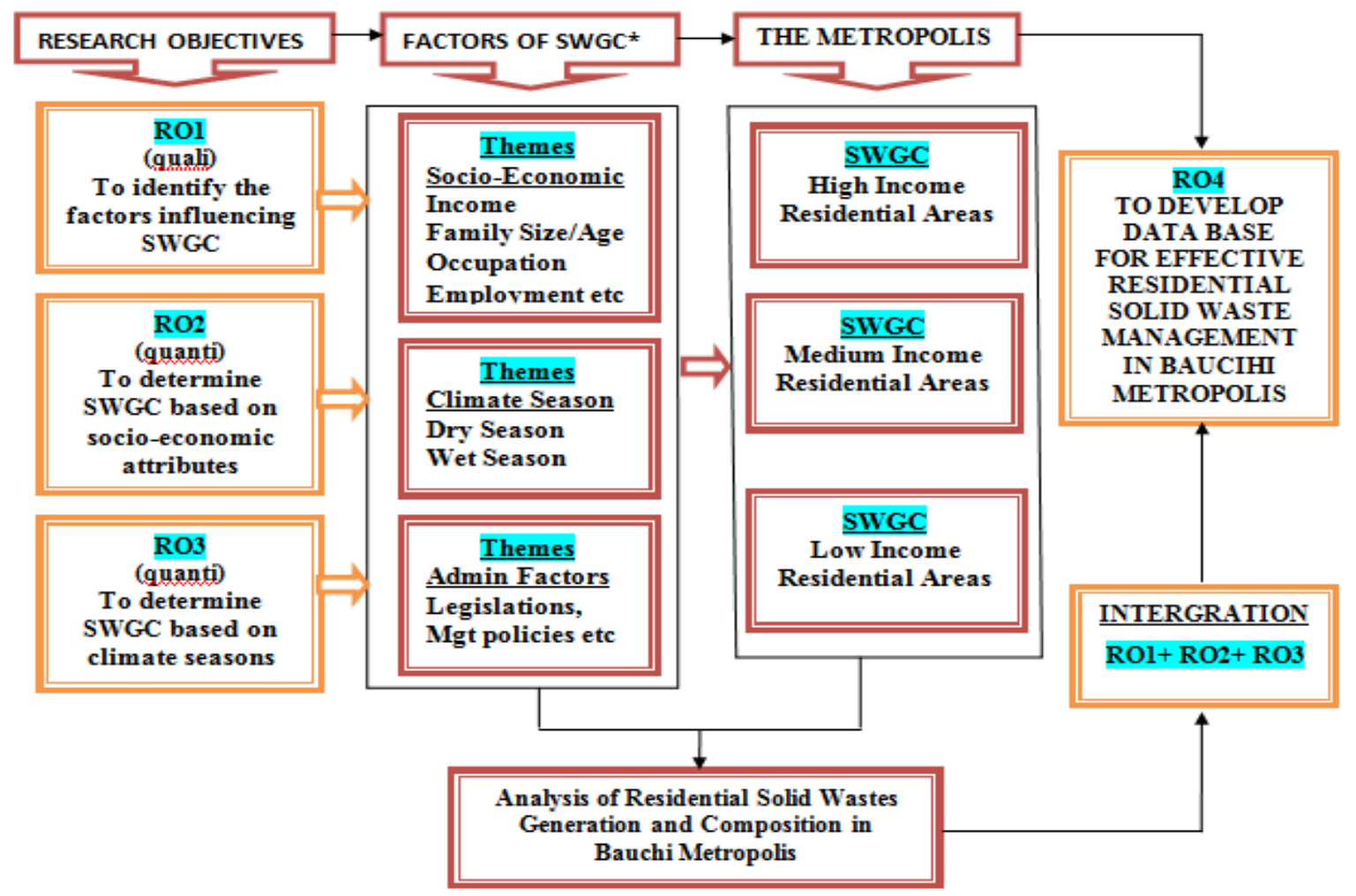

Figure 2: A Proposed theoretical framework for analysis of residential solid waste generation and composition in bauchi metropolis, Nigeria.

\section{Conclusion}

The paper portrays the need for a framework for data analysis on solid wastes generation and composition and proposed a framework for such analysis using Bauchi metropolis as a case study. The paper also portrays the relevance of databases in deciding appropriate policies for effective waste management for cities in developing countries. Further research is recommended to explore more areas of improving on the proposed theoretical framework.

\section{REFERENCES:}

[1] L. A. Guerrero, M. Ger and H. William, Solid waste management challenges for cities in developing countries. Waste management 33.1 (2013) 220-232

[2] P. Modak, Municipal solid waste management: Turning waste into resources. Shanghai Manual-A Guide for Sustainable Urban Development in the 21st Century, (2011) 2-5.

[3] E. C. Ezeah, Analysis of barriers and success factors affecting the adoption of sustainable management of municipal solid waste in Abuja, Nigeria. (2010).

[4] U. N. Ngoc, and H. Schnitzer, Sustainable solutions for solid waste management in Southeast Asian countries. Waste Management 29.6 (2009) 1982-1995.

[5] P. Beigl, L. Sandra, and S. Stefan, Modelling municipal solid waste generation: A review. Waste management 28.1 (2008) 200-214.

[6] S. Ojeda-Benitez, A. V. Carolina and E. R. Ma Characterization and quantification of household solid wastes in a Mexican city. Resources, Conservation and Recycling 39.3 (2003) 211-222 
[7] E. D. Boer, A. Jędrczak, Z. Kowalski, J. Kulczycka and R. Szpadt, A review of municipal solid waste composition and quantities in Poland. Waste management 30.3 (2010) 369-377.

[8] S. J. Burnley, A review of municipal solid waste composition in the United Kingdom. Waste Management 27.10 (2007) 1274-1285.

[9] M. Sujauddin, S. M. S. Huda, and A. T. M. Hoque, Household solid waste characteristics and management in Chittagong, Bangladesh. Waste Management 28.9 (2008) 1688-1695.

[10] M. B. Dangi, C. R. Pretz, M. A. Urynowicz, K. G. Gerow and J. M. Reddy, Municipal solid waste generation in Kathmandu, Nepal. Journal of environmental management 92.1 (2011) 240249.

[11] A. O. Afon, and O. Afolabi, Estimating the quantity of solid waste generation in Oyo, Nigeria. Waste management \& research 25.4 (2007) 371-379.

[12] S. R. M., Yatima, and A. A. Mohd., Household Solid Waste Characteristics and Management in Low Cost Apartment in Petaling Jaya, Selangor. Health and the Environment Journal 1.2 (2010).

[13] M. Asase, E. K. Yanful, M. Mensah, J. Stanford and S. Amponsah, Comparison of municipal solid waste management systems in Canada and Ghana: a case study of the cities of London, Ontario, and Kumasi, Ghana. Waste Management 29.10 (2009) 2779-2786. 